\title{
Dynamic Active Earth Pressures of the Retaining Piles with Anchors under Vehicle Loads
}

\author{
Hong-zhi Qiu, ${ }^{1,2}$ Ji-ming Kong, ${ }^{1}$ and Ren-chao Wang ${ }^{1,2}$ \\ ${ }^{1}$ Key Laboratory of Mountain Hazards and Earth Surface Processes, Institute of Mountain Hazards and Environment, \\ Chinese Academy of Sciences, Chengdu, Sichuan 610041, China \\ ${ }^{2}$ University of Chinese Academy of Science, Beijing 100049, China \\ Correspondence should be addressed to Hong-zhi Qiu; hnqhz@126.com and Ji-ming Kong; jimingk@imde.ac.cn
}

Received 17 July 2015; Revised 23 October 2015; Accepted 4 November 2015

Academic Editor: Sundararajan Natarajan

Copyright (C) 2016 Hong-zhi Qiu et al. This is an open access article distributed under the Creative Commons Attribution License, which permits unrestricted use, distribution, and reproduction in any medium, provided the original work is properly cited.

\begin{abstract}
The pile-anchor supporting structure is widely used in foundation pit engineering; then knowledge of active earth pressure on piles is very important for engineers. In this paper, based on the pseudodynamic method and considering the vehicle's vibration characteristic, a method to calculate the earth pressure on piles under vehicle load is presented. At the same time, the constraint of anchor is simplified relation of lateral deformation of piles in present method. Effects of a wide range of parameters like rupture angle, vibration acceleration coefficient, wall friction angle, and soil friction angle on active earth pressure have been studied. Results are presented in terms of coefficients in the figures and comparison of the test data and the earth pressure calculated by M-O method and present study. The result shows that the measured earth pressure is accordant with the theoretical analysis, so the method in this paper is an effective basis for the calculation of earth pressure on piles under vehicle loads.
\end{abstract}

\section{Introduction}

In design and construction of the excavation, the calculation problem of earth pressure has been encountered by engineers. There are a lot of deep excavations in center area of the city, where dense urban roads traffic is heavy. In particular, the project of urban road expansion, during construction of the road, keeps working. When foundation pit is close to driving roads, it can cause the damage of retaining structure for underestimating the vehicle vibration on the impact of foundation pit supporting structure (see Figure 1). Usually these typical examples can be commonly found in large- and medium-size cities in China. Therefore, calculating the earth pressure on retaining piles close to road in the design and construction of foundation pit, we must consider the impact of vehicle loads.

In the past few decades, though the calculation method of earth pressure on retaining structure has been greatly developed, achievements are mainly focused on the dynamic response of the structure subjected to dynamic loads such as earthquake and vehicle loads $[1,2]$. Under earthquake loads, the methods have been developed to evaluate the seismic earth pressure on a rigid retaining structure, being known as the pseudostatic method first used by Okabe [3] and Mononobe and Matsuo [4]. Pseudostatic method is an extension of the Coulomb sliding wedge theory, which was later recognized as famous Mononobe-Okabe method [5]. Steedman and Zeng [6] proposed a pseudodynamic method, which assumes that the walls and high seismic acceleration versus time were sinusoidal variation, and the shear modulus and shear wave velocity are also identified as a limited value; the study shows that the pseudodynamic method is closed actually. Then, Zeng and Steedman [7] also show that the earth pressure in pseudodynamic method is in agreement with the centrifugal modeling results, confirming that the proposed method is correct.

Pseudodynamic method is used to calculate the earth pressure on retaining walls under earthquake; the results are more accurate compared to the static method [8-12]. Study on supporting structure under the vehicle load is mainly in the dynamic characteristics of the supporting structures [13, 14 ] and the stability of supporting structures [15]. However, in the calculation method of earth pressure behind the supporting piles, effects of vehicle vibration characteristics are rarely 

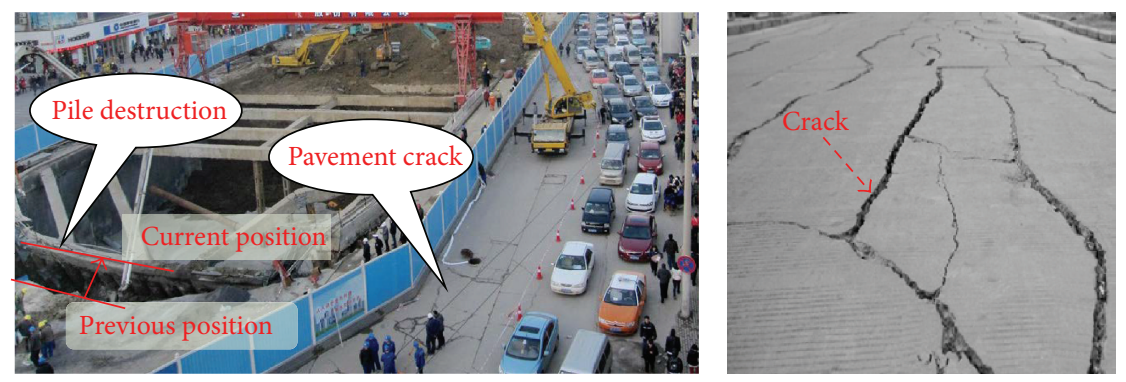

Pavement crack

FIgURE 1: Typical example of pit destruction [16].

taken into account. In addition, there is no consideration of the constraint of anchor structures in solution of earth pressure on retaining piles.

In the past, solving the earth pressure on supporting structure is based on static method $[17,18]$, and vehicle loads are simplified equal static load; results of calculation show that the error is relatively large and cannot reflect the soil pressure in practice. Thus, in this work, a distribution of earth pressure on supporting structure under vehicle load is presented; we have considered the contribution of anchor structures on earth pressure on piles. Moreover, effects of a wide range of parameters like vibration acceleration coefficient, wall friction angle, soil friction angle, and the weight of the soil on active earth pressure have been studied. Finally, comparison of the earth pressure is calculated by $\mathrm{M}-\mathrm{O}$ method and present study and test data; a suggestion has been given to calculate earth pressure on pile under vehicle loads.

\section{Method of Analysis}

2.1. Response Acceleration. The growth of heavy vehicle loads poses a threat to the safety of infrastructure. Dynamic stress and acceleration response analysis is important for design and assessment of structure [19, 20]. Acceleration induced by vehicle loads was obtained by experiment [21, 22]. The experimental results show that characters measured acceleration response versus time is similar to acceleration induced by earthquake. Therefore, this paper assumes that the vehicle generates shear and primary waves.

Pseudodynamic method assumes that the rock mass shear modulus $G$ does not change over vertical position of the slope; namely, $G$ is a constant. Supporting piles at depth $z$ by horizontal and vertical vibration accelerations is defined as $a_{h}(z, t)$ and $a_{V}(z, t)$, respectively, where $z$ is depth below the surface of the soil vibration acceleration at time $t$ for the following equation [6]:

$$
\begin{aligned}
& a_{h}(z, t)=k_{h} g \cdot \sin \left[\omega\left(t-\frac{z}{V_{s}}\right)\right], \\
& a_{V}(z, t)=k_{V} g \cdot \sin \left[\omega\left(t-\frac{z}{V_{p}}\right)\right],
\end{aligned}
$$

where $k_{h}$ is the horizontal vibration acceleration coefficient, $k_{V}$ is the vertical vibration acceleration coefficients, $z$ is

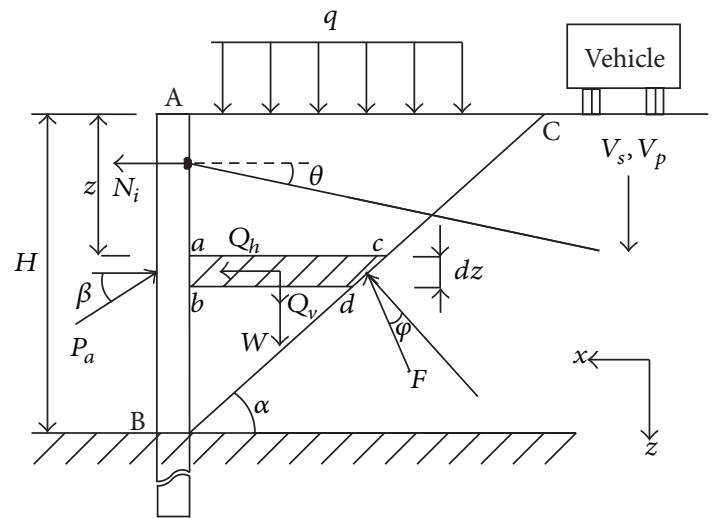

FIgURE 2: Model for computation earth pressure on piles under vehicle loads.

the depth of the underground, $\omega$ is the angular frequency of the wave vibration, and $V_{s}$ and $V_{p}$ are the velocity of shear wave and vertical wave, respectively:

$$
\begin{aligned}
& V_{s}=\sqrt{\frac{G}{\rho},} \\
& V_{p}=\sqrt{\frac{G(2-2 \mu)}{\rho(1-2 \mu)}},
\end{aligned}
$$

where $G$ is the shear modulus of soil and $\rho$ and $\mu$ are the density of pile soil and Poisson's ratio, respectively.

For the majority of geological material, $V_{p} / V_{s}=1.87$ [23], and vibration cycle is $T=2 \pi / \omega=4 H / V_{s}$ [24].

2.2. Analytical Model. Based on the character of the research problem, the active earth pressure behind retaining piles has been analyzed by using pseudodynamic approach under vehicle loads. According to practical engineering problems, analysis model is shown in Figure 2.

The soil behind the piles from an equilibrium state to another equilibrium state in Figure 3 and the position $A B$ moves to a new location $A^{\prime} B^{\prime}$, so a slight angle $\delta$ is generated; at the same time, the pile shows a slight lateral deformation $\Delta l$. We assume that the lateral deformation of pile is approximately equal to the elongation of anchor structure, and the tensile force of anchor is $\Delta N$ determined 


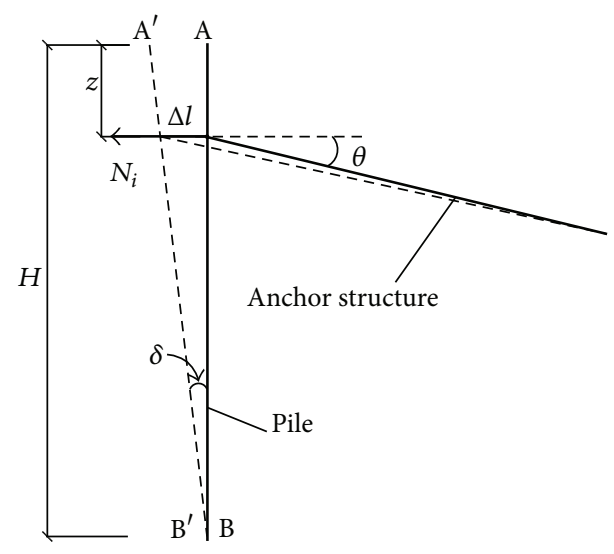

FIGURE 3: Lateral deformation of pile-anchor support structure.

by the elongation of anchor, which distributed continuously with the depth:

$$
\Delta l=(H-z) \theta
$$

where $H$ is a length of cantilever retaining piles.

According to the principle of force equilibrium, the tensile force acting on the piles in depth $z$ is given by

$$
\Delta N=\Delta l E A_{a}=(H-z) \theta E A_{a},
$$

where $E$ is elastic modulus of anchor structure and $A_{a}$ is sectional area of the anchor structure.

Tension generated by anchor structure is assumed to be evenly distributed along the length of pile, and then the total force can be expressed as

$$
N=\int_{0}^{H} \Delta N d z=\frac{1}{2} H^{2} \theta E A_{a} .
$$

From Figure 2 in the limit equilibrium soil wedge $\mathrm{ABC}$, taking $d z$ thickness analysis unit body as an object,

$$
\begin{aligned}
& \overline{a c}=(H-z) \cot \alpha, \\
& \overline{b d}=(H-z-d z) \cot \alpha .
\end{aligned}
$$

Then, the area of the horizontal bar $d z$ is

$$
S_{a c d b}=\frac{1}{2}(\overline{b d}+\overline{a c}) d z .
$$

The quality of the horizontal bar $d z$ is

$$
\Delta m=\rho S_{a c d b}=\rho(H-z) \cot \alpha d z .
$$

The weight of the soil wedge is

$$
W=\int_{0}^{H} \rho g(H-z) \cot \alpha d z=\frac{1}{2} \gamma H^{2} \cot \alpha,
$$

where $\gamma$ is the unit weight of the soil, $\gamma=\rho g$.
The total horizontal inertia force acting within the failure zone is given by

$$
\begin{aligned}
Q_{h}(z, t)= & \int_{0}^{H} \Delta m a_{h}(z, t) \\
= & \frac{\lambda_{s} \gamma k_{h} \cot \alpha}{2 \pi} \\
& \cdot\left[\frac{\lambda_{s}}{2 \pi}(\sin \omega t-\sin \omega \eta)-H \cos \omega t\right],
\end{aligned}
$$

where $\lambda_{s}$ is the transverse wavelength $\lambda_{s}=V_{s} / f$ and the angular frequency $\omega=2 \pi f$, making $\eta=t-H / V_{s}$.

Similarly, the total vertical inertial force acting on the failure wedge is given by

$$
\begin{aligned}
Q_{V}(z, t)=\int_{0}^{H} \Delta m a_{V}(z, t) \\
\quad=\frac{\lambda_{p} \gamma k_{V} \cot \alpha}{2 \pi}\left[\frac{\lambda_{p}}{2 \pi}(\sin \omega t-\sin \omega \xi)-H \cos \omega t\right],
\end{aligned}
$$

where $\lambda_{p}$ is the longitudinal wave $\lambda_{p}=V_{p} / f, V_{p} / \omega=\lambda_{p} / 2 \pi$, making $\xi=t-H / V_{p}$.

According to the equilibrium of the forces on piles in Figure 2, the total active thrust can be obtained, so $P_{a}$ can be expressed as follows:

$$
\begin{aligned}
P_{a} & \\
= & \frac{\cos (\alpha-\varphi) Q_{h}+\sin (\alpha-\varphi) Q_{V}+\sin (\alpha-\varphi) W}{\cos (\alpha-\varphi-\beta)} \\
& +\frac{\cot \alpha \sin (\alpha-\varphi) q H+\cos (\alpha-\varphi+\theta) N}{\cos (\alpha-\varphi-\beta)} .
\end{aligned}
$$
$K_{a}$,

Assuming that the coefficient of active earth pressure is

$$
K_{a}=\frac{2 P_{a}}{\gamma H^{2}}
$$

Substituting for $Q_{h}$ and $Q_{V}$ in (13), an expression for $K_{a}$ in terms of $Q_{h}, Q_{V}, W$, and $N$ can be derived:

$$
\begin{aligned}
K_{a}= & \frac{\cos (\alpha-\varphi) \cot \alpha k_{h}}{2 \pi^{2} \cos (\alpha-\varphi-\beta)} \frac{T V_{s}}{H} a_{1} \\
& +\frac{\sin (\alpha-\varphi) \cot \alpha k_{V}}{2 \pi^{2} \cos (\alpha-\varphi-\beta)} \frac{T V_{p}}{H} a_{2} \\
& +\frac{\cot \alpha \sin (\alpha-\varphi)}{\cos (\alpha-\varphi-\beta)}+\frac{2 q \cot \alpha \sin (\alpha-\varphi)}{\gamma H \cos (\alpha-\varphi-\beta)} \\
& +\frac{\cos (\alpha-\varphi+\theta) \theta E A_{a}}{\gamma \cos (\alpha-\varphi-\beta)}
\end{aligned}
$$




$$
\begin{aligned}
a_{1}= & \frac{T V_{s}}{H}\left[\sin 2 \pi\left(\frac{t}{T}\right)-\sin 2 \pi\left(\frac{t}{T}-\frac{H}{T V_{s}}\right)\right] \\
& -2 \pi \cos 2 \pi\left(\frac{t}{T}\right), \\
a_{2}= & \frac{T V_{p}}{H}\left[\sin 2 \pi\left(\frac{t}{T}\right)-\sin 2 \pi\left(\frac{t}{T}-\frac{H}{T V_{p}}\right)\right] \\
& -2 \pi \cos 2 \pi\left(\frac{t}{T}\right) .
\end{aligned}
$$

From (14) it can be analyzed that active earth pressure coefficient is the function of $\alpha, t / T, H / T V_{s}$, and $H / T V_{V}$. In most geological materials $H / T V_{s}$ and $H / T V_{p}$ values are 0.25 and 0.134 , respectively. And then we can take the partial derivative with respect to $P_{a}(z, t)$ as distribution of earth pressure with depth:

$$
\begin{aligned}
& p_{a}(z, t)=\frac{\partial P_{a}(z, t)}{\partial z} \\
& =\frac{\cos (\alpha-\varphi) T V_{s}}{\cos (\alpha-\varphi-\beta) 2 \pi} \gamma k_{h}(\cot \alpha) b_{1} \\
& +\frac{\sin (\alpha-\varphi) T V_{p}}{\cos (\alpha-\varphi-\beta) 2 \pi} \gamma k_{V}(\cot \alpha) b_{2} \\
& +\frac{\sin (\alpha-\varphi) \cot \alpha q}{\cos (\alpha-\varphi-\beta)} \\
& +\frac{\sin (\alpha-\varphi) z \gamma \cot \alpha}{\cos (\alpha-\varphi-\beta)} \\
& +\frac{\cos (\alpha-\varphi+\theta) z \theta E A_{a}}{\cos (\alpha-\varphi-\beta)} \\
& b_{1}=\left[\cos 2 \pi\left(\frac{t}{T}-\frac{z}{T V_{s}}\right)-\cos 2 \pi\left(\frac{t}{T}\right)\right] \text {, } \\
& b_{2}=\left[\cos 2 \pi\left(\frac{t}{T}-\frac{z}{T V_{p}}\right)-\cos 2 \pi\left(\frac{t}{T}\right)\right] \text {. }
\end{aligned}
$$

According to (15), dynamic active earth pressures on piles for foundation pit contain three parts:

$$
\begin{aligned}
p_{a}(z, t)= & p_{a d}+p_{a s}+p_{a t}, \\
p_{a d}= & \frac{\cos (\alpha-\varphi) T V_{s}}{\cos (\alpha-\varphi-\beta) 2 \pi} \gamma k_{h}(\cot \alpha) b_{1} \\
& +\frac{\sin (\alpha-\varphi) T V_{p}}{\cos (\alpha-\varphi-\beta) 2 \pi} \gamma k_{V}(\cot \alpha) b_{2},
\end{aligned}
$$

$$
\begin{aligned}
p_{a s}= & \frac{\cot \alpha \sin (\alpha-\varphi) q}{\cos (\alpha-\varphi-\beta)} \\
& +\frac{\sin (\alpha-\varphi)}{\cos (\alpha-\varphi-\beta)} z \gamma \cot \alpha, \\
p_{a t}= & \frac{\cos (\alpha-\varphi+\theta) z \theta E A_{a}}{\cos (\alpha-\varphi-\beta)} .
\end{aligned}
$$

$p_{a d}$ is the dynamic earth pressure created by vehicle loads; $p_{a s}$ is the static earth pressure created by the weight of soils and the static load on the ground; $p_{a t}$ is the tensile force produced by anchor structure.

2.3. Computation of Rupture Angle ( $\alpha$ ). It can be shown from (15) that earth pressure distribution function $p_{a}(z, t)$ is related to the following parameters: $\varphi, \beta, \gamma, k_{h}, k_{V}$, and $f_{a}$. And test shows that the soil pressure after pile varies with time and different depth $z$. When the sliding mass attains limiting equilibrium condition, the active earth pressure after pile $P_{a}(z, t)$ reached a maximum. Thus, the angle of sliding surface inclination and also the angle of rupture can be obtained by partial differential equation $\partial P_{a}(z, t) / \partial \alpha=0$. After simplifying,

$$
\begin{aligned}
& {\left[\frac{-\sin \beta \cot \alpha}{\cos ^{2}(\alpha-\varphi-\beta)}-\frac{\cos (\alpha-\varphi)}{\cos (\alpha-\varphi-\beta) \sin ^{2} \alpha}\right] \frac{\lambda_{s} \gamma k_{h}}{2 \pi}} \\
& \cdot m_{1}+\left[\frac{\cos \beta \cot \alpha}{\cos ^{2}(\alpha-\varphi-\beta)}\right. \\
& \left.-\frac{\sin (\alpha-\varphi)}{\cos (\alpha-\varphi-\beta) \sin ^{2} \alpha}\right] \frac{\lambda_{V} \gamma k_{V}}{2 \pi} m_{2} \\
& +\frac{\gamma H^{2}}{2}\left[\frac{\cos \beta \cot \alpha}{\cos ^{2}(\alpha-\varphi-\beta)}\right. \\
& \left.-\frac{\sin (\alpha-\varphi)}{\cos (\alpha-\varphi-\beta) \sin ^{2} \alpha}\right]+q H\left[\frac{\cot \alpha \cos (\alpha-\varphi)}{\cos (\alpha-\varphi-\beta)}\right. \\
& \left.-\frac{\sin (\alpha-\varphi)}{\cos (\alpha-\varphi-\beta) \sin ^{2} \alpha}\right]-\frac{\sin (\beta+\theta) H^{2} \delta E A_{a}}{2 \cos ^{2}(\alpha-\varphi-\beta)} \\
& =0 \text {, } \\
& m_{1}=\frac{\lambda_{s}}{2 \pi}\left[\sin 2 \pi\left(\frac{t}{T}\right)-\sin 2 \pi\left(\frac{t}{T}-\frac{H}{T V_{s}}\right)\right]-H \\
& \cdot \cos 2 \pi\left(\frac{t}{T}\right) \\
& m_{2}=\frac{\lambda_{V}}{2 \pi}\left[\sin 2 \pi \frac{t}{T}-\sin 2 \pi\left(\frac{t}{T}-\frac{H}{T V_{p}}\right)\right]-H \\
& \cdot \cos 2 \pi\left(\frac{t}{T}\right) .
\end{aligned}
$$

Equation (17) is a function of the time $t$ and the inclination angle $\alpha$ of the slide surface, abbreviated as $f(t, \alpha)=0$. Therefore, the angle of rupture will be obtained by drawing 


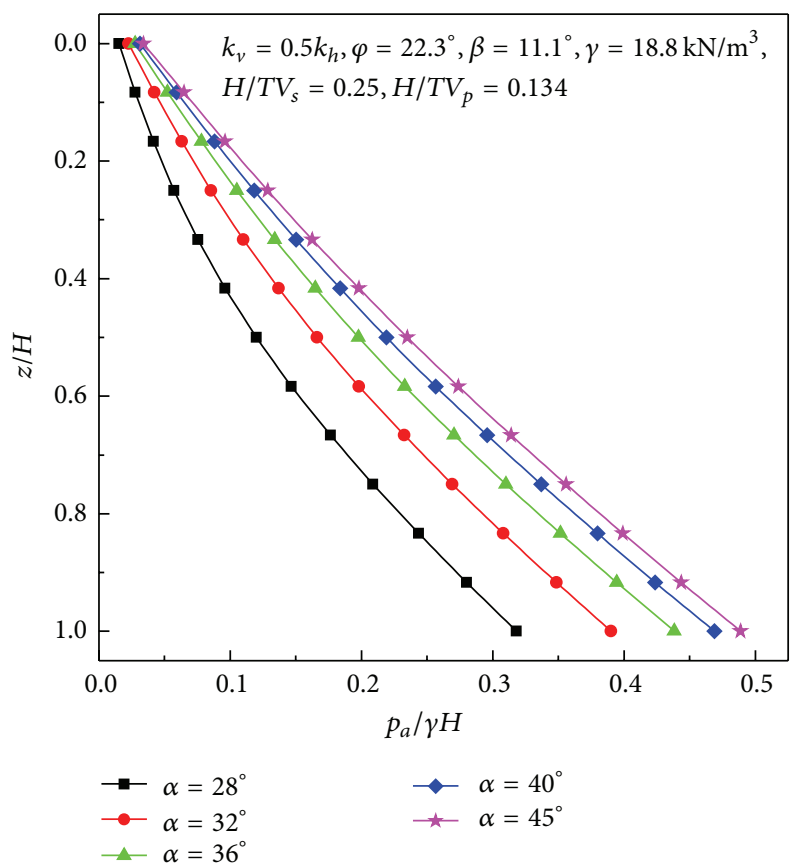

FIGURE 4: Active earth pressure distribution for different values of rupture angle, $\alpha$.

the soil pressure distribution curve since corresponding angle $\alpha_{i}$ at any time will all work out.

\section{Results and Discussion}

3.1. Effect of Rupture Angle ( $\alpha$ ). Figure 4 shows the distributions of active earth pressure for values of rupture angle $\alpha$ with $k_{V}=0.5 k_{h}, k_{h}=0.05, \varphi=22.3^{\circ}, \beta=\varphi / 2$, $\gamma=18.8 \mathrm{kN} / \mathrm{m}^{3}, H / T V_{s}=0.25$, and $H / T V_{p}=0.134$. With the increasing of rupture angle $\alpha$, active earth pressure increased. Plots show that when $\alpha$ change from $28^{\circ}$ to $32^{\circ}$, the active earth pressure increases by $16.29 \mathrm{kN}$; namely, when each degree increases in rupture angle $\alpha$, the active earth pressure increased by $4.07 \mathrm{kPa}$.

Similarly, when $\alpha$ change from $32^{\circ}$ to $36^{\circ}$, a total of the active earth pressure increases by $10.81 \mathrm{kPa}$ and the average of active earth pressure increased by $2.7 \mathrm{kPa}$ for each degree. The value of increment in active earth pressure decreased with increase at the same angle $(\alpha)$. Therefore, the greater the rupture angle, the smaller the impact range on the earth pressure. The dotted line represents the dynamic earth pressure produced by vehicle loads; the solid line represents the static earth pressure in Figure 5. Results show that the value of rupture angle decreases, with increase in proportion of dynamic earth pressure. Moreover, the greater the rupture angle, the smaller the dynamic earth pressure.

In Figure 6, the solid line represents the dynamic earth pressure produced by the horizontal inertia force, and the dotted line represents the dynamic earth pressure produced by the vertical inertial force; comparing the two values, results show that the vertical inertial force has a marginal effect

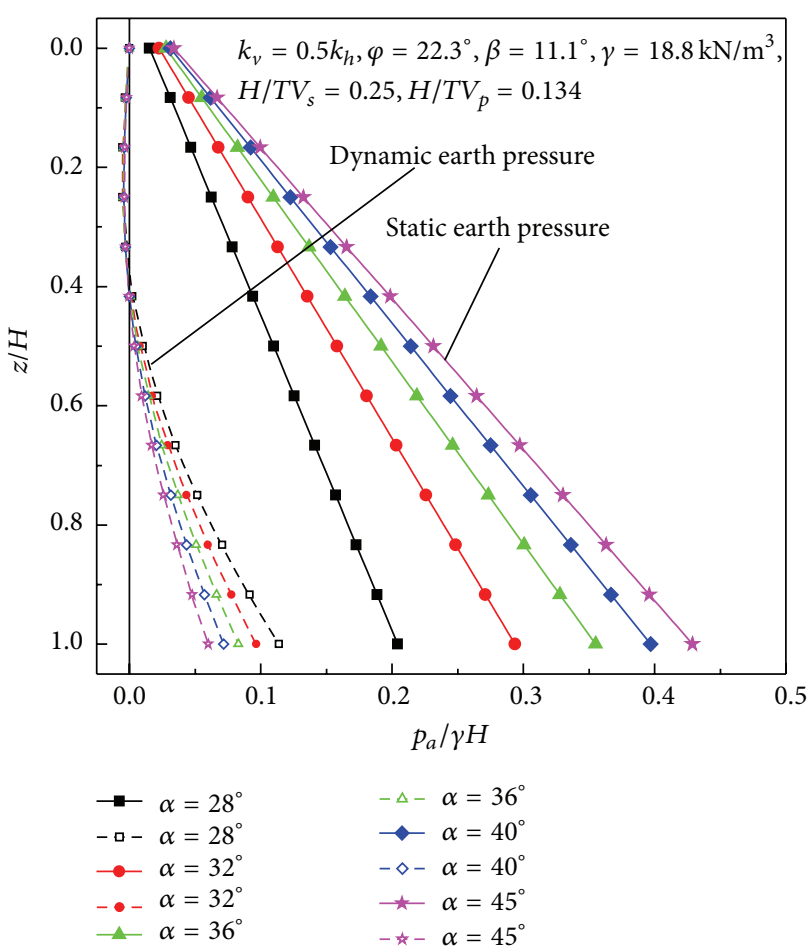

FIGURE 5: Comparisons of static and dynamic soil pressure.

on the dynamic earth pressure and thus contributions to dynamic earth pressure are mainly horizontal inertia force.

3.2. Effect of $k_{h}$ and $k_{V}$. According to the definition of the acceleration coefficient, $k_{h}$ can indirectly reflect the value of inertial force by dynamic loads.

Figure 7 shows a plot of the distributions of active earth pressure for values of $k_{h}$ with $k_{V}=0.5 k_{h}, \varphi=22.3^{\circ}, \beta=\varphi / 2$, $\gamma=18.8 \mathrm{kN} / \mathrm{m}^{3}, H / T V_{s}=0.25$, and $H / T V_{p}=0.134$. The plot shows that, at more than half the height of the pile, the impact on the earth pressure is very small and active earth pressure decreases with the increase of coefficient, $k_{h}$. At less than half the height of the pile, earth pressure is greatly influenced by $k_{h}$ and active earth pressure increases with the acceleration coefficient increase.

3.3. Effect of Soil Friction Angle $(\varphi)$. Figure 8 shows the distributions of active earth pressure for values of soil friction angle $\varphi$ with $k_{V}=0.5 k_{h}, k_{h}=0.05, \beta=\varphi / 2, \gamma=18.8 \mathrm{kN} / \mathrm{m}^{3}$, $H / T V_{s}=0.25$, and $H / T V_{p}=0.134$. When $\varphi$ change from $18^{\circ}$ to $26^{\circ}$, active earth pressure changes from $152.67 \mathrm{kPa}$ to $105.69 \mathrm{kPa}$, which decreases by about $30.77 \%$. In other words, each degree increased in the soil friction angle $\varphi$, and then active earth pressure decreases by $5.9 \mathrm{kPa}$.

3.4. Effect of Wall Friction Angle ( $\beta$ ). Figure 9 shows the distributions of active earth pressure for values of wall friction angle $\beta$ with $k_{V}=0.5 k_{h}, k_{h}=0.05, \varphi=20^{\circ}, \gamma=18.8 \mathrm{kN} / \mathrm{m}^{3}$, $H / T V_{s}=0.25$, and $H / T V_{p}=0.134$. Active earth pressure shows relatively marginal decrease with the increase in wall friction angle $\beta$. When $\beta$ change from $0^{\circ}$ to $\varphi / 2$, the active 


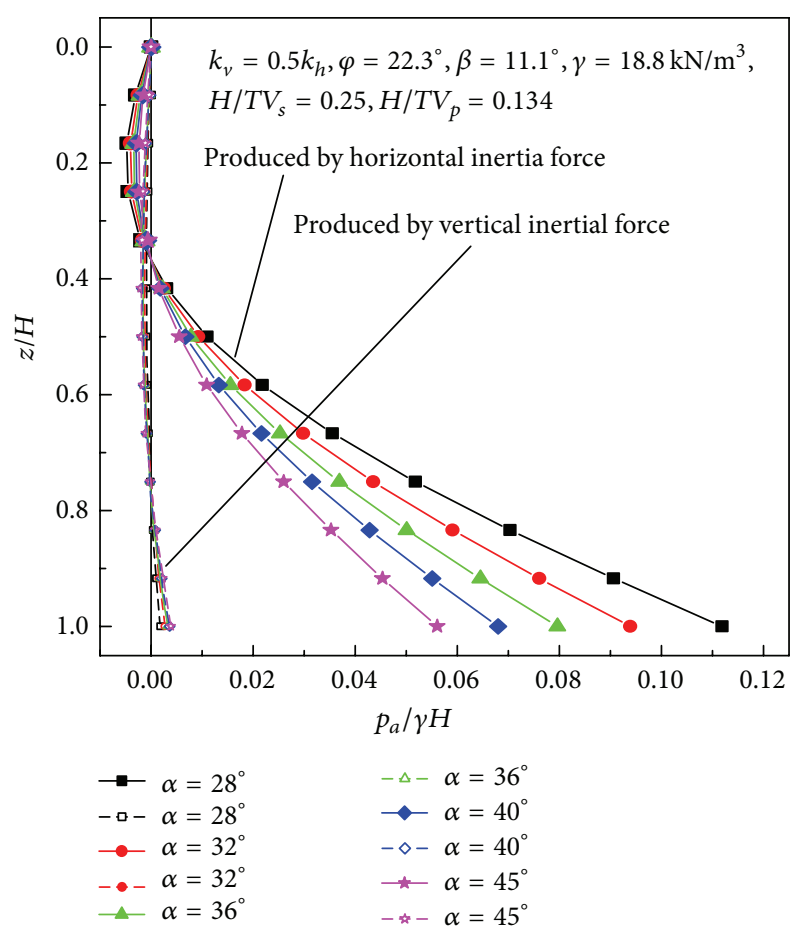

Figure 6: Comparisons of dynamic earth pressures produced by the horizontal inertia force and the vertical inertial force.

earth pressure decreases by $3.48 \%$, and when $\beta$ change from $0^{\circ}$ to $\varphi$, the active earth pressure decreases by $3.65 \%$.

From (12), it can be learned that the generation of active earth pressure on retaining structure consists of three parts, including inertia force generated by vehicle loads, tension of anchor, and the gravity of soil wedge. The wall friction angle has no effect on the total earth pressure. In addition, the wall friction angle in the formula is only a denominator, calculating the distribution of earth pressure with depth. The denominator is a function of three angles, one of the angles changes, and the others change as well. Therefore, the relation between all angles is to ensure that the denominator is positive and the effect of the wall friction angle $\beta$ is not worth mentioning.

3.5. Comparison of Results. In order to certify that present study method is effective, Figure 10 shows the comparison of the test data and the active earth pressure calculated by Mononobe-Okabe method and present study with $k_{V}=$ $0.5 k_{h}, k_{h}=0.04, \varphi=22.3^{\circ}, \beta=\varphi / 2, \gamma=18.8 \mathrm{kN} / \mathrm{m}^{3}$, $H / T V_{s}=0.25$, and $H / T V_{p}=0.134$; the above parameters are obtained by experience.

It is evident from Figure 10 that active earth pressure calculated by present study is close to the test data; result obtained by Mononobe-Okabe method is relatively large. What is more, distributions of active earth pressure calculated by present study and test data show clearly nonlinear vibration of vehicle loads. It is also clear from Steedman and Zeng $[6,7]$ that the dynamic earth pressure distribution along the height is nonlinear.

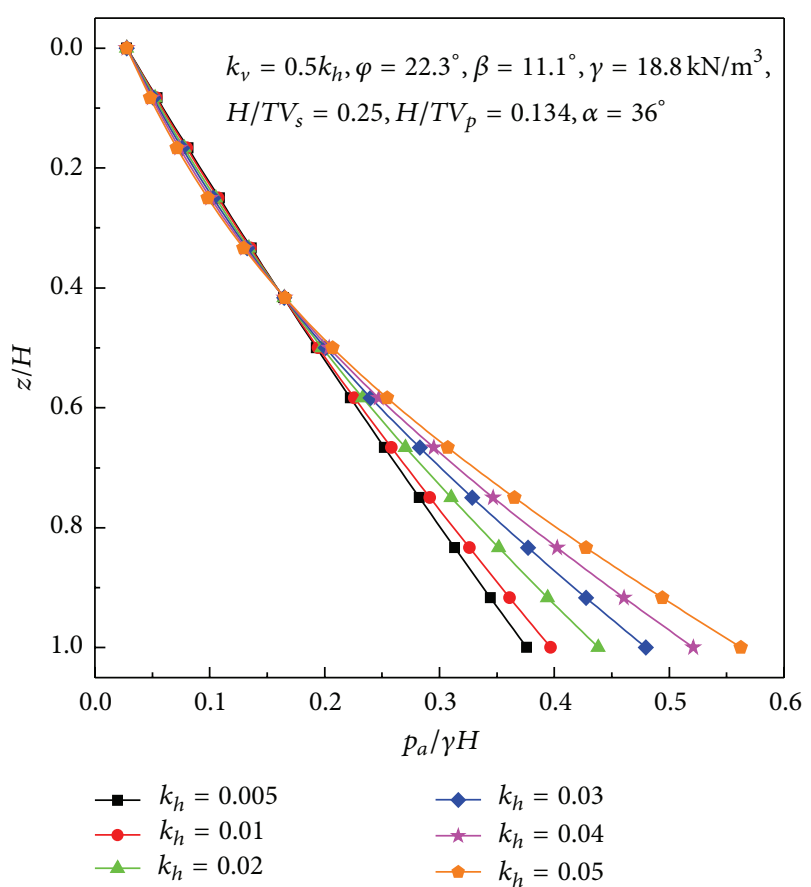

FIgURE 7: Active earth pressure distribution for different values of $k_{h}$ with $k_{V}=0.5 k_{h}$.

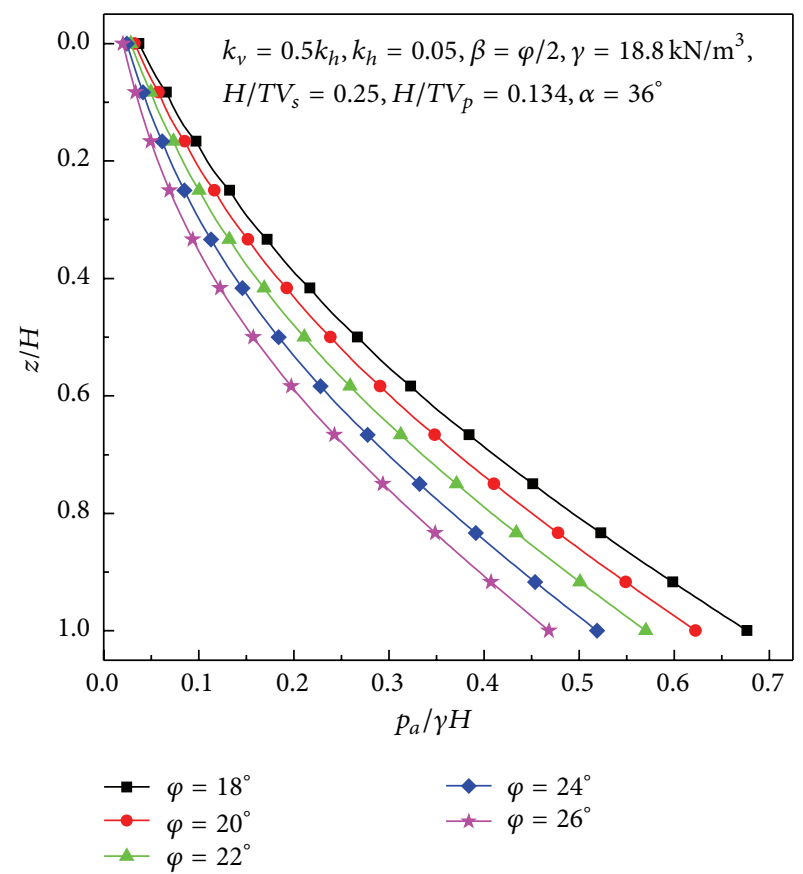

FIGURE 8: Active earth pressure distribution for different values of soil friction angle, $\varphi$.

\section{Conclusions}

Pile-anchor retaining structure is the type of deep foundation pit retaining system most frequently used in China. In this work, based on the pseudodynamic method, a solution was presented for calculating active earth pressures on piles in 


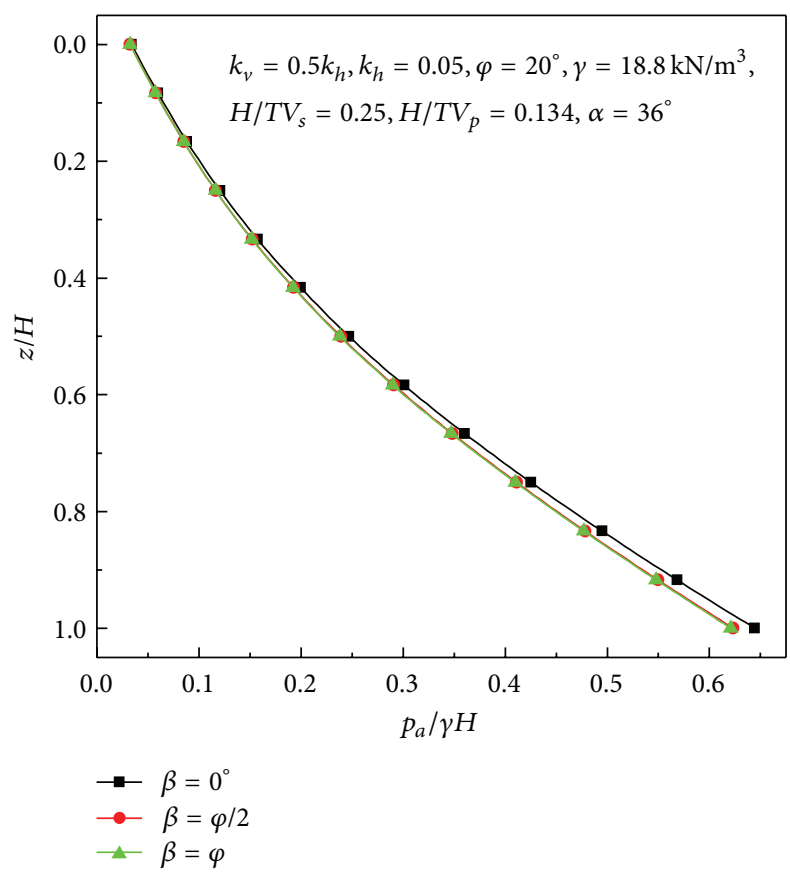

FIGURE 9: Active earth pressure distribution for different values of wall friction angle, $\beta$.

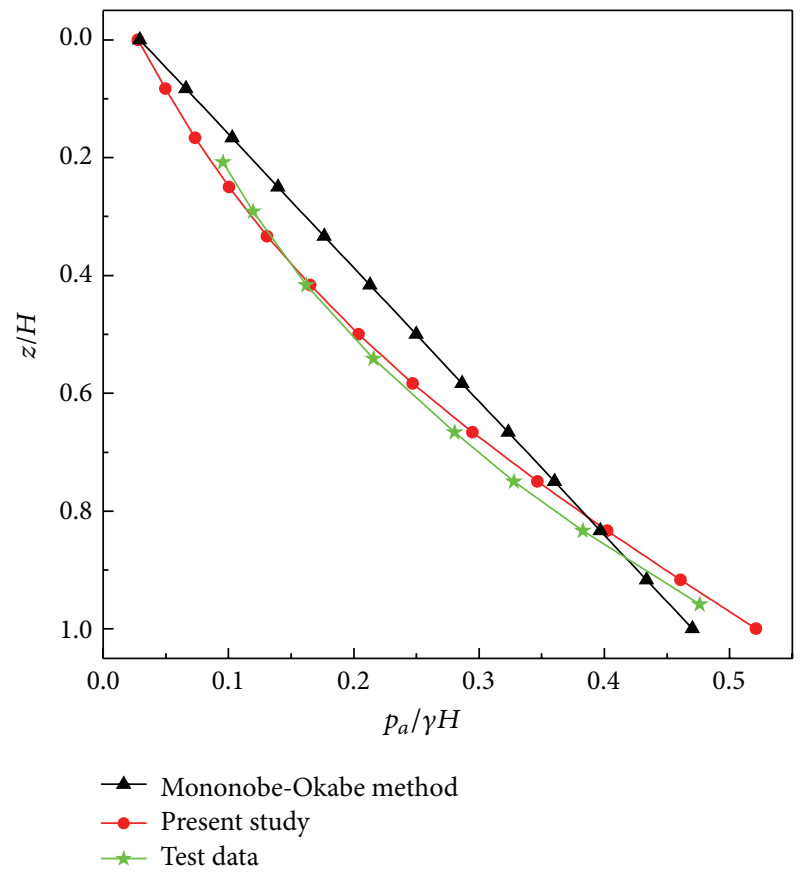

FIGURE 10: Typical comparison results for $k_{h}=0.04, k_{V}=0.02$, $\varphi=22.3^{\circ}, \beta=11.1^{\circ}$, and $\gamma=18.8 \mathrm{kN} / \mathrm{m}^{3}$.

deep pits. The proposed solution incorporates vibration of vehicle loads, retaining structure deformations and material properties. The following are the main conclusions of the study:

(1) In present method, by considering the effect of vehicle loads and the constraint of anchor structures, the solution to calculate the active earth pressure on piles under vehicle loads is obtained. The paper presents effects of parameters on earth pressure, such as rupture angle, horizontal and vertical vibration coefficient, soil friction angle, and wall friction angle.

(2) The results of present analysis show that the earth pressure increases with the increase in rupture angle, $\alpha$, and horizontal and vertical vibration coefficient, $k_{h}$ and $k_{V}$, which have a great influence on the earth pressure on piles. The active earth pressure is highly sensitive to the friction angle of the soil, $\varphi$, and comparatively less sensitive to the wall friction angle, $\beta$.

(3) The typical results of distribution of the earth pressure on piles show the high nonlinearity. Under the influence of many factors, the distribution of dynamic earth pressure generated by vehicle loads with depth is nonlinear, which have a great contribution to the active earth pressure on piles. In comparison of the test data and the results calculated by present study and Mononobe-Okabe method, the results show that the earth pressure gained by the proposed method coincides well with the test data. This work provides a method to calculate earth pressure on piles required for the design purpose.

\section{Nomenclature}

$G: \quad$ Shear modulus of soil

$a_{h}(z, t)$ : Horizontal vibration acceleration

$a_{V}(z, t)$ : Vertical vibration acceleration

$k_{h}$ : Horizontal vibration acceleration coefficient

$k_{V}$ : Vertical vibration acceleration coefficients

$z: \quad$ Depth of the underground

$\omega: \quad$ Angular frequency of the wave vibration

$H: \quad$ Height of the retaining piles

$V_{s}: \quad$ Shear wave velocity of vibration wave

$V_{p}: \quad$ Vertical wave velocity of vibration wave

$\rho: \quad$ Density of soil wedge

$\mu$ : $\quad$ Poisson's ratio

E: $\quad$ Elastic modulus of anchor structure

$\gamma: \quad$ Unit weight of the soil

$\lambda_{s}: \quad$ Transverse wavelength

$\lambda_{p}: \quad$ Longitudinal wave

$\alpha: \quad$ Rupture angle

$\varphi: \quad$ Soil friction angle

$\beta$ : $\quad$ Rupture angle

$\theta: \quad$ Horizontal angle anchor.

\section{Conflict of Interests}

The authors declare that there is no conflict of interests regarding the publication of this paper.

\section{Acknowledgments}

This research was supported by National High Technology Research and Development Program of China ("863" Project, no. 2012AA121302). In addition, NetEase News provided image information for this work. 


\section{References}

[1] K. S. Subba Rao and D. Choudhury, "Seismic passive earth pressures in soils," Journal of Geotechnical and Geoenvironmental Engineering, vol. 131, no. 1, pp. 131-135, 2005.

[2] A.-H. Soubra, "Static and seismic passive earth pressure coefficients on rigid retaining structures," Canadian Geotechnical Journal, vol. 37, no. 2, pp. 463-478, 2000.

[3] S. Okabe, "General theory of earth pressure," Journal of Japan Society of Civil Engineers, vol. 12, no. 1, 1926 (Japanese).

[4] N. Mononobe and H. Matsuo, "On the determination of earth pressure during earthquakes," in Proceedings of the World Engineering Conference, vol. 9, pp. 177-185, Tokyo, Japan, 1929.

[5] R. V. Whitman, "Seismic design of earth retaining structures," in Proceedings of the 2nd International Conference on Recent Advances in Geotechnical Earthquake Engineering and Soil Dynamics, pp. 1767-1778, St. Louis, Mo, USA, March 1991.

[6] R. S. Steedman and X. Zeng, "The influence of phase on the calculation of pseudo-static earth pressure on a retaining wall," Geotechnique, vol. 40, no. 1, pp. 103-112, 1990.

[7] X. Zeng and R. S. Steedman, "On the behaviour of quay walls in earthquakes," Geotechnique, vol. 43, no. 3, pp. 417-431, 1993.

[8] D. Choudhury and S. S. Nimbalkar, "Pseudo-dynamic approach of seismic active earth pressure behind retaining wall," Geotechnical and Geological Engineering, vol. 24, no. 5, pp. 1103-1113, 2006.

[9] Z.-K. Wang, T.-D. Xia, and W.-Y. Chen, "Pseudo-dynamic analysis for seismic active earth pressure behind rigid retaining wall," Journal of Zhejiang University (Engineering Science), vol. 46, no. 1, pp. 46-51, 2012 (Chinese).

[10] P. Ghosh, "Seismic passive earth pressure behind non-vertical retaining wall using pseudo-dynamic analysis," Geotechnical and Geological Engineering, vol. 25, no. 6, pp. 693-703, 2007.

[11] S. Ghosh, "Pseudo-dynamic active force and pressure behind battered retaining wall supporting inclined backfill," Soil Dynamics and Earthquake Engineering, vol. 30, no. 11, pp. 12261232, 2010.

[12] A. Azad, S. S. Yasrobi, and A. Pak, "Seismic active pressure distribution history behind rigid retaining walls," Soil Dynamics and Earthquake Engineering, vol. 28, no. 5, pp. 365-375, 2008.

[13] C. Lin, Y.-F. Luo, and S.-P. Wang, "Monitoring and effect of moving load to foundation excavation support configuration," Journal of Wuhan University of Technology, vol. 29, no. 11, pp. 112-114, 2007 (Chinese).

[14] J. C. Yue, H. Z. Qiu, and L. J. Zhang, "Analysis on dynamic response of the foundation pit supporting structure under traffic loads," Chinese Journal of Underground Space and Engineering, vol. 9, no. 6, pp. 1320-1325, 2013 (Chinese).

[15] X. D. Zhang, C. G. Zhang, and J. S. Liu, "Analysis on stability of deep foundation pit supporting structure under traffic load," The Chinese Journal of Geological Hazard and Control, vol. 22, no. 2, pp. 125-129, 2011 (Chinese).

[16] Netease news, "The supporting structure of pit fracture and the subway construction site collapsed in Wuhan city, China," 2012, http://news.163.com/photoview/00AN0001/30678.html.

[17] J.-J. Wang and H.-J. Chai, "Active earth pressure induced by saturated sub grade under vehicle load," Chinese Journal of Geotechnical Engineering, vol. 30, no. 3, pp. 372-378, 2008 (Chinese).

[18] Specifications for Design of Highway Asphalt Pavement (JTGD50-2006), China Communication Press, Beijing, China, 2006 (Chinese).
[19] H. Zhang, X. Xie, J. Q. Jiang, and M. Yamashita, “Assessment on transient sound radiation of a vibrating steel bridge due to traffic loading," Journal of Sound and Vibration, vol. 336, pp. 132-149, 2015.

[20] Y. L. Xu, Q. Li, D. J. Wu, and Z. W. Chen, "Stress and acceleration analysis of coupled vehicle and long-span bridge systems using the mode superposition method," Engineering Structures, vol. 32, no. 5, pp. 1356-1368, 2010.

[21] H. Aied, A. González, and D. Cantero, "Identification of sudden stiffness changes in the acceleration response of a bridge to moving loads using ensemble empirical mode decomposition," Mechanical Systems and Signal Processing, vol. 66-67, pp. 314338, 2016.

[22] H. Z. Qiu, J. M. Kong, R. C. Wang et al., "Analyzing the effects of active earth pressure on supporting piles under vehicle loads," Chinese Journal of Geotechnical Engineering, 2015 (Chinese).

[23] D. Choudhury and S. Nimbalkar, "Seismic passive resistance by pseudo-dynamic method," Geotechnique, vol. 55, no. 9, pp. 699702, 2005.

[24] S. L. Kramer, Geotechnical Earthquake Engineering, Prentice Hall, Upper Saddle River, NJ, USA, 1990. 


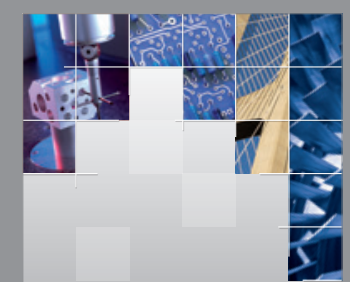

\section{Enfincering}
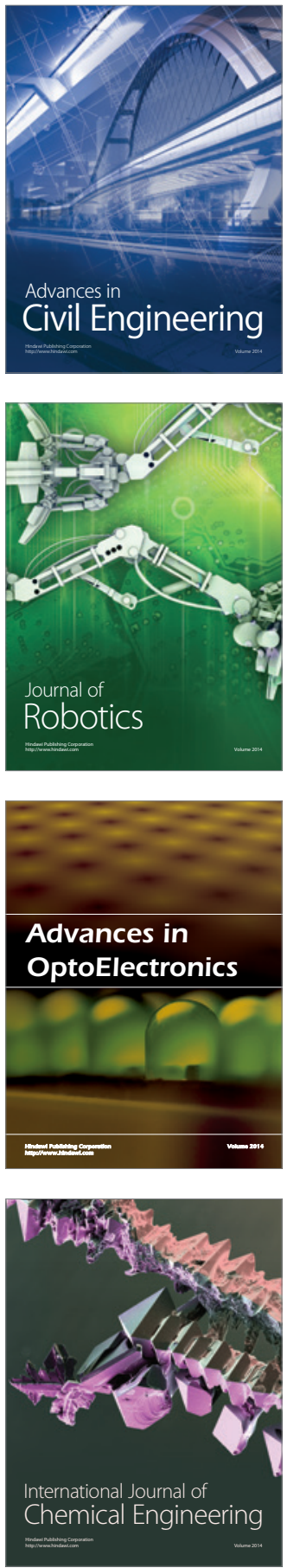

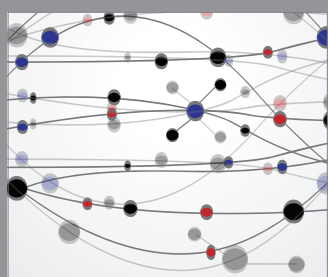

The Scientific World Journal

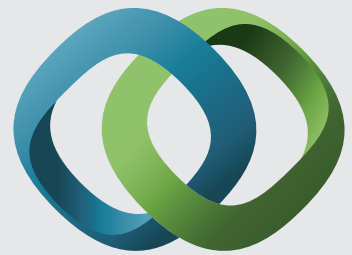

\section{Hindawi}

Submit your manuscripts at

http://www.hindawi.com
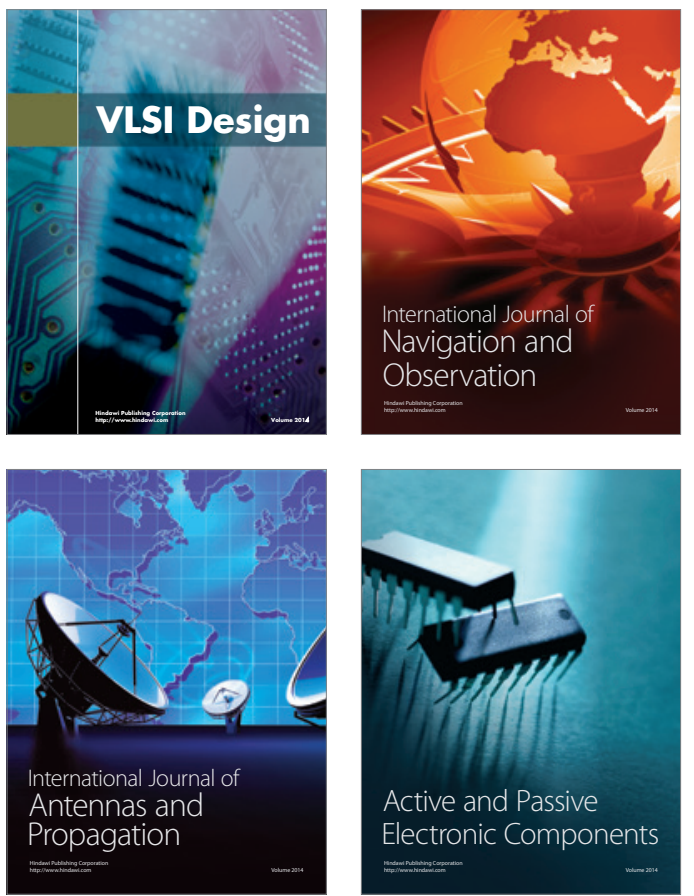
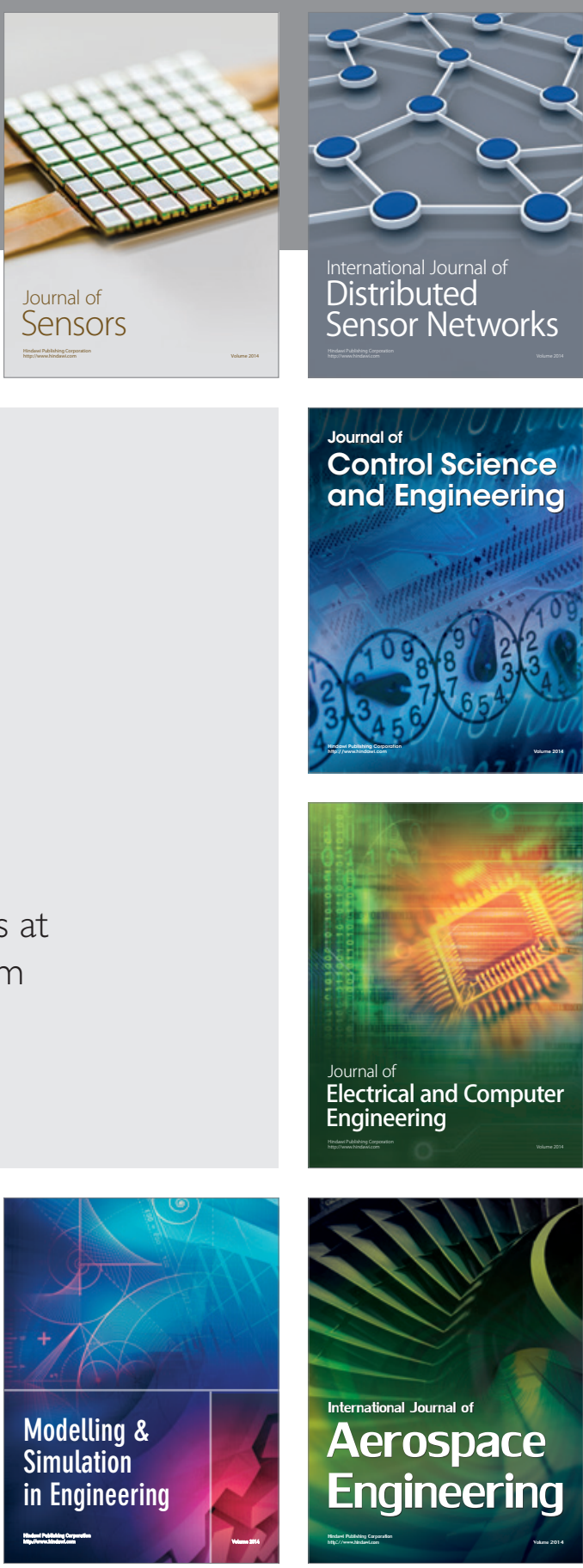

International Journal of

Distributed

Sensor Networks

Journal of

Control Science

and Engineering
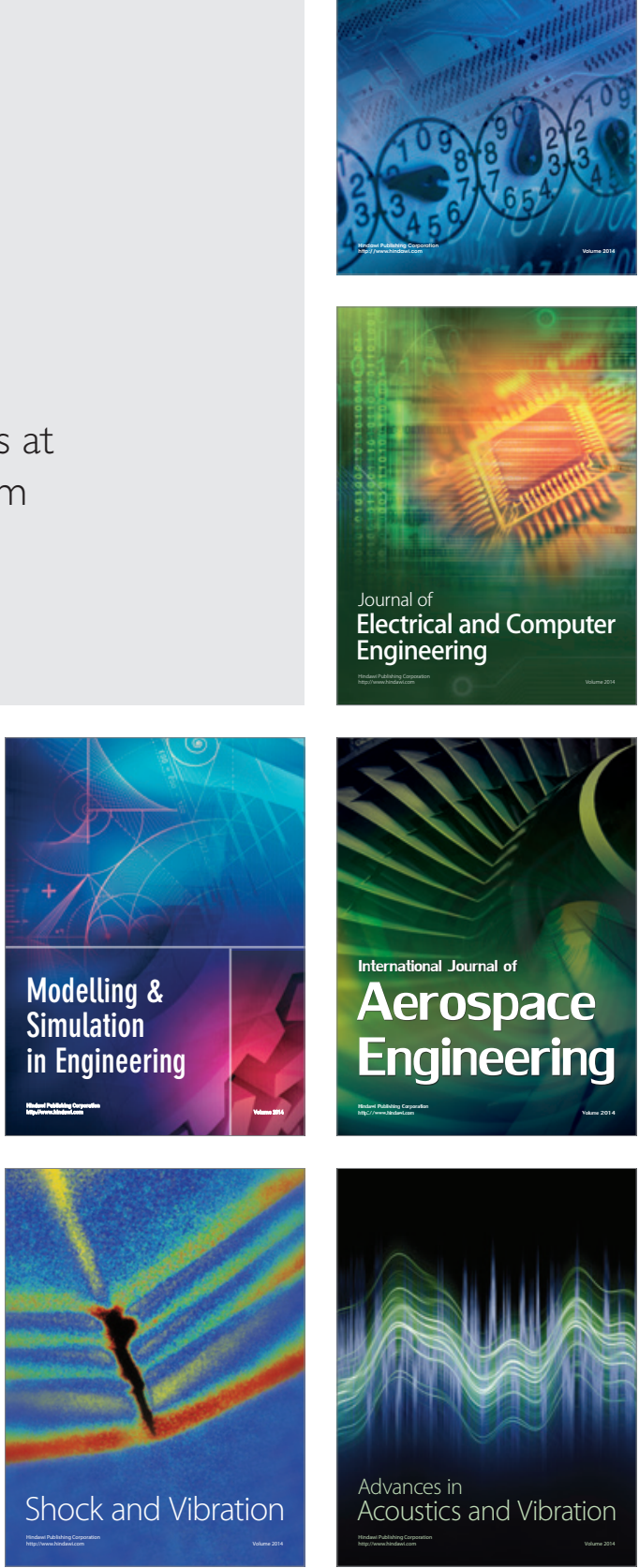